\title{
Avaliação de um kit de imunoensaio cromatográfico para detecção do antígeno do vírus da cinomose em cães com sinais sistêmicos ou neurológicos da doença
}

\section{Evaluation of a commercial kit of chromatographic immunoassay for detection of canine distemper antigen in dogs with systemic or neurologic signs of the disease}

\author{
Murilo Cézar Curti1 ; Mônica Vicky Bahr Arias²*; Marcelo de Souza Zanutto ${ }^{3}$
}

\begin{abstract}
Resumo
A cinomose é uma doença multisistêmica altamente contagiosa, que pode levar a graves sequelas e até ao óbito. Diferentes tipos de exames podem ser usados para o diagnóstico ante mortem da cinomose, entretanto, devido ao curso imprevisível da doença, o diagnóstico final permanece incerto em alguns casos. O objetivo deste trabalho foi avaliar a eficácia do teste comercial de imunoensaio cromatográfico para detecção de antígeno $(\mathrm{Ag})$ da cinomose em 33 cães com suspeita de cinomose canina, comparandose ainda a frequência dos sinais clínicos e neurológicos entre cães positivos e negativos. Em 27/33 o material foi coletado da mucosa ocular, em $5 / 33$ foi coletado do LCR e em um animal o material foi coletado da mucosa ocular e do LCR. Em 14/33 cães foi realizada também a técnica da reação em cadeia da polimerase precedida de transcrição reversa (RT-PCR). O teste do Ag foi positivo em 7/13 casos confirmados, sendo que todos esses apresentavam sinais sistêmicos, porém em nenhum cão que apresentou apenas sinais neurológicos o teste do Ag foi positivo. Em seis cães negativos pelo teste do antígeno o resultado da RT-PCR foi positivo. Os resultados obtidos neste trabalho evidenciaram que o teste do Ag não auxiliou no diagnóstico da cinomose em muitos casos com sinais sistêmicos e neurológicos, permitindo ainda que vários casos apresentassem resultados falso-negativos.
\end{abstract}

Palavras-chave: Cães, sistema nervoso, diagnóstico, cinomose

\begin{abstract}
The canine distemper is a multisystemic disease highly contagious which can lead to serious consequences and even to death. Different types of tests can be used for the ante mortem diagnosis of canine distemper, however, due to unpredictable course of the disease, the final diagnosis remains uncertain in some cases. We evaluated in 33 dogs with suspected canine distemper, the effectiveness of a commercial test for detection of antigen ( $\mathrm{Ag}$ ) of canine distemper, still comparing the frequency of clinical and neurological signs among positive and negative dogs. In 27/33 dogs the material was collected from the ocular mucosa, in 5/33 dogs the test was performed with CSF and in one animal material was collected from the ocular mucosa and CSF. In 14 dogs was performed also the RT-PCR technique. The Ag test was positive in 7/13 confirmed cases of canine distemper, all of them with systemic signs, but in dogs that had only neurologic signs, the antigen test was negative. In six dogs the antigen test was negative, however the RT-PCR was positive. The results of this study showed that the antigen test did not help for the canine distemper diagnosis in many cases with systemic and neurologic signs, still allowing that several cases had false-negative results.
\end{abstract}

Key words: Dogs, nervous system, diagnosis, canine distemper

\footnotetext{
Médico Veterinário Autônomo, Centro Veterinário SOS Animal Maringá, Maringá, PR. E-mail: muriloccurti@hotmail.com Prof $^{a} \mathrm{Dr}^{\mathrm{a}}$ Associada, Dept ${ }^{\mathrm{o}}$ de Clínicas Veterinárias, Universidade Estadual de Londrina, UEL, Londrina, PR. E-mail: vicky@uel.br Prof. Adjunto, Dept ${ }^{\circ}$ de Clínicas Veterinárias, UEL, Londrina, PR. E-mail: mzanutto@uel.br Autor para correspondência
} 
Acinomose é uma doença multisistêmica causada por um Paramyxoviridae do gênero Morbilivirus. É uma doença altamente contagiosa sendo transmitida por aerossóis para o trato respiratório superior (FRISK et al., 1999; AMUDE; ALFIERI; ALFIERI, 2006b; MARTELLA; ELIA; BUONAVOGLIA, 2008), invadindo vários tecidos inclusive o sistema nervoso central (SNC) levando a graves sequelas e até ao óbito. A infecção em cães pode apresentar-se sob as formas sistêmica e neurológica, sendo que na forma sistêmica ocorrem alterações oculares, respiratórias, gastrintestinais e dermatológicas (VANDEVELDE; CACHIN, 1993; KOUTINAS et al., 2002; AMUDE; ALFIERI; ALFIERI, 2006a; AMUDE; ALFIERI; ALFIERI, 2006b; SILVA et al., 2007; MARTELLA; ELIA; BUONAVOGLIA, 2008; FERNÁNDEZ; BERNARDINI, 2010). Os sinais neurológicos mais observados são: mioclonias, ataxia, convulsões e andar em círculos (MORITZ; FRISK; BAUMGARTNER, 2000; KOUTINAS et. al., 2002).

Devido ao curso variável e imprevisível da doença, duração da viremia e manifestações orgânicas diversas, o diagnóstico desta doença muitas vezes é incerto ou baseado em critérios clínicos (FRISK et al., 1999), sendo um desafio para o veterinário de pequenos animais, principalmente quando apenas sinais neurológicos estão presentes (AMUDE; ALFIERI; ALFIERI, 2006b), o que limita a aplicação dos exames laboratoriais in vivo existentes. A grande variedade de sinais, comuns a muitas doenças infecciosas e inflamatórias do sistema nervoso, dificulta o diagnóstico conclusivo. O diagnóstico precoce é importante para o estabelecimento do prognóstico, exclusão de outras causas e cuidado adequado com os contactantes, principalmente quando animais com sinais sugestivos são atendidos em hospitais veterinários (VANDEVELDE; CACHIN, 1993; KOUTINAS et al., 2002; GEBARA et al., 2004; NGHIEM; SCHATZBERG, 2010).

Os métodos de diagnóstico disponíveis são o isolamento viral, detecção de vírus ou seus produtos em amostras clínicas (métodos diretos) e detecção e quantificação de anticorpos antivirais específicos (métodos indiretos), cada técnica com seu mérito e limitação (VANDEVELDE; CACHIN, 1993; GEBARA et al., 2004). Todos os testes são realizados em laboratório, o que implica em custo e tempo para a sua realização, sendo que para alguns testes o ideal é o uso de tecido cerebral para confirmação da doença, enquanto outros exames apresentam resultados variáveis dependendo da fase da infecção e níveis de anticorpos do paciente (FRISK et al., 1999).

Seria interessante que um teste acessível para o clínico de pequenos animais permitisse o diagnóstico precoce, principalmente quando se considera a necessidade de internamento de animais com sinais inespecíficos da doença e o risco de transmissão da cinomose para outros cães. Recentemente, visando suprir esta necessidade, foi comercializado um kit de imunoensaio cromatográfico para detecção de antígeno (Ag) da cinomose em cães, para uso em clínicas e consultórios, nos quais amostras de urina, saliva, soro, plasma ou líquor são utilizados com o objetivo de detectar a proteína $\mathrm{F}$ do envelope do vírus. Assim, o objetivo deste trabalho foi a avaliação da eficácia deste kit, comparando-se quando possível o resultado com a RT-PCR.

Foram avaliados 33 cães que possuíam sinais clínicos e/ou neurológicos sugestivos de cinomose, trazidos por seus proprietários para atendimento no Hospital Veterinário da Universidade Estadual de Londrina, sendo 19 machos e 14 fêmeas. Devido à suspeita de cinomose, os animais não foram internados no HV/UEL. Após a realização do exame físico e neurológico, foram realizados exames laboratoriais para confirmação ou exclusão de outras doenças infecciosas ou inflamatórias que cursam com sinais clínicos semelhantes aos de cinomose. Foram coletados materiais biológicos para realização de hemograma completo e de acordo com as suspeitas clínicas realizou-se urinálise, creatinina, albumina, proteína total, glicemia, alanina transferase (ALT), fosfatase alcalina 
(FA), análise de líquido cefalorraquidiano (LCR), sorologia de toxoplasmose e reação da polimerase em cadeia (PCR) para ehrliquiose.

Em todos os cães foi realizado o teste para detecção de antígeno (Ag) conforme consta na bula do produto denominado Anigen CDV-Ag®, laboratório Bioeasy (Figura 1). Este teste utiliza um sistema de fase sólida em que os anticorpos específicos na superfície de placas ou tubos reagem contra a amostra teste contendo o vírus suspeito, permitindo a análise visual do resultado, porém de forma qualitativa. Segundo o fabricante* do kit utilizado no presente trabalho, o teste tem alta sensibilidade e especificidade quando utilizado em animais com sinais clínicos de cinomose, principalmente em swabs de conjuntiva ocular e líquor na fase crônica da doença.

Figura 1. A. Kit Anigen CDV-Ag®, laboratório Bioeasy. Na figura superior, presença de duas bandas rosa, uma sob a banda $\mathrm{C}$, controle, e a outra sob a letra $\mathrm{T}$, teste, indicando um teste com resultado positivo. Na figura inferior, presença de uma banda rosa sob a letra $\mathrm{C}$, indicando que o teste foi válido mas o resultado negativo.

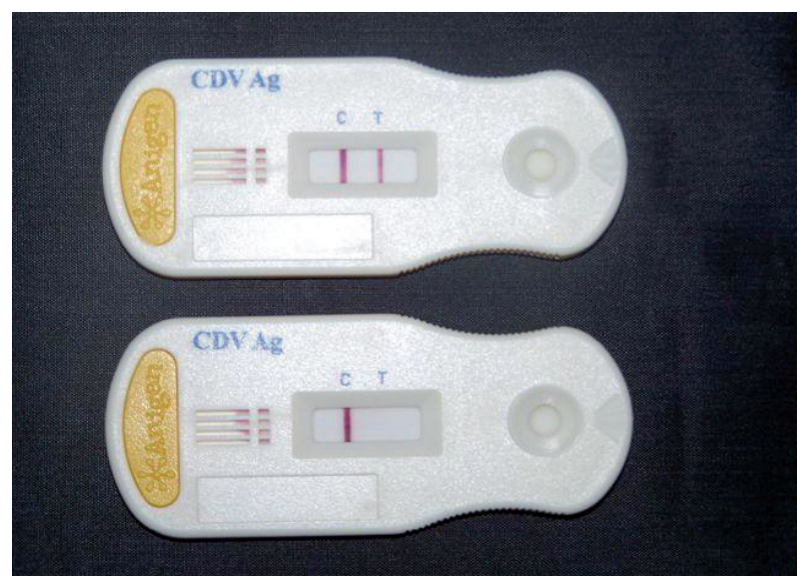

Fonte: Elaboração dos autores.

Em 27/33 cães o material foi coletado da mucosa ocular, em 5/33 cães foi coletado do LCR e em um animal o material foi coletado da mucosa ocular e do LCR. O resultado foi interpretado dez minutos após a adição do material coletado ao reagente no dispositivo do teste. Em 14 cães foi realizada também a técnica da reação em cadeia da polimerase precedida de transcrição reversa (RT-PCR) para cinomose, da urina, sangue e LCR quando colhido. Em um animal, cujo resultado do teste do Ag e da RT-PCR havia sido negativo, foi realizado exame histopatológico e RT-PCR para cinomose do material coletado do sistema nervoso durante a necropsia.
Foi utilizado o teste de Fisher com nível de significância de 5\% para avaliação dos resultados, através do pacote estatístico EPI 6. Apesar da impossibilidade da realização da RT- PCR em todos os animais, a analise estatística comparou os dois testes e sua eficácia entre animais com sinais sistêmicos e os que apresentavam apenas sinais neurológicos. Os valores preditivos positivos e negativos, bem como a concordância de Kappa não foram adotados neste estudo devido ao pequeno tamanho da amostra e porque o intervalo de confiança (IC95\%) desses resultados seria grande e comprometeria a precisão dos mesmos, da mesma forma que a medida de associação de Odds Ratio.

\footnotetext{
* Anigen Rapid CDV Ag Test Kit. Bioeasy Diagnostica Ltda. Belo Horizonte, MG.
} 
Foram avaliados 33 animais, constatando-se sinais sistêmicos em dez animais, neurológicos em 16 animais e ambos os sinais em sete. Todos os cães com sinais sistêmicos tinham menos de nove meses e os que apresentavam apenas sinais neurológicos mais de cinco anos de idade. Em 26/33 cães o resultado do teste do kit de imunoensaio cromatográfico foi negativo e em 7/33 casos o resultado foi positivo, a partir de material coletado da mucosa ocular. Em todos estes, havia a presença de sinais sistêmicos, sendo que em cinco deles havia secreção ocular. Dos 14 exames de RT-PCR realizados, o resultado foi positivo em nove animais (Tabela 1). O teste do Ag foi positivo em 7/13 casos confirmados, sendo que todos esses apresentavam sinais sistêmicos, porém em nenhum cão que apresentou apenas sinais neurológicos o teste do Ag foi positivo. Em seis animais com sinais sistêmicos, neurológicos ou ambos e com cinomose confirmada pela RT-PCR, o teste do Ag foi negativo. Em três dos sete casos diagnosticados pelo teste do antígeno, o diagnóstico também foi positivo pela técnica de RTPCR. No total, o diagnóstico de cinomose canina foi confirmado em 13 cães. Dos 23 cães com sinais neurológicos, em seis foi realizado o teste do Ag no LCR, porém todos os resultados foram negativos. Entretanto, no teste da RT-PCR, 2/6 foram positivos. Em 20/33 animais o diagnóstico de cinomose canina não foi confirmado. A RT-PCR foi negativa em cinco animais, e nos 15 animais restantes foi realizado apenas o teste do antígeno.

Tabela 1. Presença de sinais sistêmicos com ou sem sinais neurológicos, ou somente sinais neurológicos em relação ao resultado positivo ou negativo da RT-PCR e ao resultado do teste comercial de imunoensaio cromatográfico para detecção de antígeno (Ag) da cinomose (Londrina, 2012)

\begin{tabular}{|c|c|c|c|c|}
\hline \multirow[b]{3}{*}{ Sinais Sistêmicos } & \multicolumn{2}{|c|}{ RT-PCR } & \multicolumn{2}{|c|}{$\mathrm{Ag}$} \\
\hline & positivo & negativo & positivo & negativo \\
\hline & 5 & 3 & 7 & 14 \\
\hline Somente sinais neurológicos & 4 & 2 & 0 & 12 \\
\hline \multirow{2}{*}{ Total } & 9 & 5 & 7 & 26 \\
\hline & \multicolumn{2}{|c|}{14} & \multicolumn{2}{|c|}{33} \\
\hline
\end{tabular}

Fonte: Elaboração dos autores.

Não foi observada diferença estatística $(p=0,218)$ entre os dois testes em animais com sinais sistêmicos, entretanto, a RT-PCR foi estatisticamente mais eficaz nos animais que apresentavam apenas sinais neurológicos $(p=0,024)$. Já os resultados da RTPCR foram similares tanto em animais com sinais sistêmicos como nos animais apenas com sinais neurológicos.

Os sinais sistêmicos dos cães positivos e negativos estão expressos na tabela 2 . Na tabela 3 estão os sinais neurológicos dos cães positivos e negativos. Todos os cães positivos, pelo teste do antígeno e/ou pela RT-PCR, apresentavam algum sinal clínico, sendo que nove apresentavam sinais sistêmicos. Ezeibe (2005) relatou que de 65 cães com cinomose, em $80 \%$ havia secreção ocular, sendo que este sinal foi encontrado em 8/13 cães com a doença confirmada no presente trabalho. Moritz, Frisk e Baumgartner (2000), observaram em 20 cães com a forma sistêmica da doença, que em $90 \%$ havia presença de pneumonia. No presente trabalho em 2/13 animais constatou-se tosse e crepitação pulmonar à auscultação.

Moritz, Frisk e Baumgartner (2000), relataram como sinais neurológicos mais observados a mioclonia (45\%), convulsão $(45 \%)$ e ataxia $(35 \%)$. No trabalho realizado por Koutinas et. al. (2002) havia mioclonia em 13/19 cães com encefalite. No presente trabalho a mioclonia não foi observada em todos os cães positivos e foi constatada em vários 
animais negativos nos testes laboratoriais. Este sinal neurológico é passível de ser observado em outras encefalites e algumas síndromes raciais raras, entretanto, a causa mais comum de mioclonia em cães é a cinomose canina (SILVA et al., 2007). O resultado do exame pode ser negativo mesmo em animais com cinomose, devido ao fato da doença estar na fase crônica e os antígenos não serem mais detectados (GREENE, 2006).

Tabela 2. Sinais sistêmicos observados em oito cães negativos no teste do antígeno e na RT-PCR e em nove cães com cinomose confirmada (Londrina, 2012).

\begin{tabular}{ccc}
\hline Sinais Sistêmicos & N negativos (8) & N positivos (9) \\
\hline Secreção ocular & 5 & 8 \\
Hipertermia & 5 & 4 \\
Aumento de linfonodo & 5 & 4 \\
Diarreia & 2 & 3 \\
Lesões dermatológicas & 1 & 3 \\
Vômito & 3 & 2 \\
Tosse & 1 & 2 \\
Crepitação Pulmonar & 1 & 2 \\
Hiperqueratose nasodigital & 0 & 2 \\
\hline
\end{tabular}

Fonte: Elaboração dos autores.

Tabela 3. Sinais neurológicos observados em sete cães com Cinomose confirmada e em 16 cães negativos no teste do antígeno e na RT-PCR. 2011.

\begin{tabular}{ccc}
\hline Sinais Neurológicos & N positivos (7) & N negativos (16) \\
\hline Ataxia/paresia/tetraparesia proprioceptivas & 3 & 8 \\
Convulsão & 2 & 0 \\
Mioclonia & 2 & 3 \\
Síndrome vestibular central & 2 & 4 \\
Cegueira central & 1 & 3 \\
Síndrome Cerebelar & 1 & 1 \\
\hline
\end{tabular}

Fonte: Elaboração dos autores.

Guedes et al. (2009) utilizaram o mesmo teste para detecção de antígeno em 101 cães com suspeita de cinomose canina, sendo que 30,6\% foram positivos, porém os autores não utilizaram outro método diagnóstico como comparativo, portanto não puderam descartar a presença de falso negativos. Pereira (2010) realizou o teste do Ag em cães submetidos à eutanásia devido à presença de sinais sistêmicos e neurológicos compatíveis com cinomose, em uma Sociedade Protetora de Animais, obtendo 31 resultados positivos em líquor de cães com sinais oculares associados a sinais neurológicos, encontrando porém corpúsculos de inclusão no globo ocular de cinco cães negativos no teste do Ag.

Pereira (2010) constatou sensibilidade de $86 \%$ e especificidade de $100 \%$ quando o teste foi realizado no líquor, considerando como padrão de comparação a presença de corpúsculo de inclusão no exame histopatológico, sendo que a bula do kit comercial indica sensibilidade de $98,9 \%$ e especificidade de $97,7 \%$. Resultados falso-negativos no diagnóstico da cinomose podem ocorrer em amostras coletadas 21 a 28 dias após a infecção, pois o vírus migra dos 
tecidos epiteliais, devido ao aumento dos anticorpos circulantes em associação com a recuperação clínica do animal. O mesmo ocorre nas formas subaguda e crônica da doença ou quando não há sinais sistêmicos (GREENE, 2006). Da mesma forma no teste de PCR pode não haver detecção do vírus em algumas amostras biológicas em animais com diagnóstico de cinomose conformada (FRISK et al., 1999; AMUDE; ALFIERI; ALFIERI, 2006b). Entretanto no presente trabalho a RT-PCR foi mais sensível que o teste do antígeno quando a amostra biológica examinada foi o líquor.

Todos os cães com sinais sistêmicos eram jovens, porém apenas cães adultos possuíam unicamente sinais neurológicos. Amude, Alfieri e Alfieri (2006b), constataram que três cães com encefalite por cinomose sem sinais sistêmicos, apresentavam mais de um ano e nove meses de idade, provavelmente decorrente da imunidade do animal, comportamento do vírus dentro do sistema nervoso e idade do paciente (GEBARA et al., 2004; AMUDE; ALFIERI; ALFIERI, 2006b; SILVA et al., 2007; FERNÁNDEZ; BERNARDINI, 2010).

Apesar do número baixo de animais testados, verificou-se que o kit de imunoensaio cromatográfico não foi eficaz para o diagnóstico da cinomose em sua formaneurológica, pois nenhumanimalapresentando apenas sinais neurológicos foi diagnosticado por este exame, porém o teste apresentou resultado positivo em cães com sinais sistêmicos. Assim, este teste não colaborou para o diagnóstico da cinomose em muitos casos, permitindo ainda a obtenção de resultados falso-negativos da doença, o que poderia levar à presença de animais infectados eliminando o vírus no ambiente e colocando em risco outros animais, dentro de uma população em que a maioria não é vacinada, caso o clínico confie somente neste exame para o diagnóstico.

\section{Agradecimentos}

À Prof $f^{\mathrm{a}}$. Dr ${ }^{\mathrm{a}}$. Roberta Lemos Freire pelo auxílio na análise estatística.

À UEL pela bolsa IC concedida.

Pesquisa de Iniciação Científica inserida no Projeto aprovado pelo CEEA/UEL of./circ CEEA № 05/2007.

\section{Referências}

AMUDE, A. M.; ALFIERI, A. A.; ALFIERI, A. F. Antemortem diagnosis of CDV infection by RT-PCR in distemper dogs with neurological deficits without the typical clinical presentation. Veterinary Research Communications, v. 30, n. 6, p. 679-687, 2006a.

. The nervous form of canine distemper. Arquivo

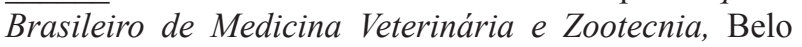
Horizonte, v. 13, n. 2, p. 125-136, 2006 b.

EZEIBE, M. C. O. Canine distemper in local dogs in Nsukka, Nigeria. The Veterinary Record, London, n. 156, p. 840-842, 2005.

FERNÁNDEZ, V. L.; BERNARDINI, M. Neurologia em cães e gatos. São Paulo: Medvet, 2010.

FRISK, A. L.; KONIG, M.; MORITZ, A.; BAUMGARTNER, W. Detection of canine distemper virus nucleoprotein RNA by reverse transcription-PCR Using serum, whole blood and ceberebrospinal fluid from dogs with distemper. Journal of Clinical Microbiology, Barcelona, v. 37, n. 11, p. 3634-3643, 1999.

GEBARA, C. M. S.; WOSIACKI, S. R.; NEGRÃO, F. J.; ALFIERI, A. A; ALFIERI, A. F. Lesões histológicas no sistema nervoso central de cães com encefalite $\mathrm{e}$ diagnóstico molecular da infecção pelo vírus da cinomose canina. Arquivo Brasileiro de Medicina Veterinária e Zootecnia, Belo Horizonte, v. 56, n. 2, p. 168-174, 2004.

GREENE, C. E. Infectious diseases of the dog and cat. 3. ed. Philadelphia: Saunders, 2006.

GUEDES, I. B.; LIMA, A. S.; ESPINHEIRO, R. F.; MANSSOUR, M. B.; CRUZ, I. P.; DIAS, H. L. T. Occurrence and geographical assessment of canine distemper in the city of Belém, Pará-Brazil. In: WORLD SMALL ANIMAL VETERINARY ASSOCIATION CONGRESS, 34., 2009, São Paulo. Proceedings... São Paulo: World Small Animal Veterinary Association, jul. 2009. 
KOUTINAS, A. F.; POLIZOPOULOU, Z. S.; BAUMGAERTNER, W.; LEKKAS, S.; KONTOS, V. Relation of clinical signs to pathological changes in 19 cases of canine distemper encephalomyelitis. Journal of Comparative Pathology, v. 126, n. 1, p. 47-56, 2002.

MARTELLA, V.; ELIA, G.; BUONAVOGLIA, C. Canine distemper virus. Veterinary Clinics of North America: Small Animal Practice, Philadelphia, v. 38, n. 4, p. 787-797, 2008.

MORITZ, A.; FRISK, A. L.; BAUMGARTNER, W. The evaluation of diagnostic procedures for the detection of canine distemper virus infection. European Journal of Companion Animal Practice, Paris, v. 10, n. 1, p. 37-47, 2000.

NGHIEM, P. P.; SCHATZBERG, S. Conventional and molecular diagnostic testing for acute neurologic patient. Journal of Veterinary Emergency and Critical Care, v. 20, n. 1, p. 46-61, 2010.
PEREIRA, F. B. Comparação de métodos de diagnóstico para a cinomose canina, com ênfase nas alterações oculares. 2010. Dissertação (Mestrado em Ciências Veterinárias) - Universidade Federal do Paraná, Curitiba.

SILVA, M. C.; FIGHERA, R. A.; BRUM, J. S.; GRAÇA, D. L.; KOMMERS, G. D.; IRIGOYEN, L. F.; BARROS, C. S. L. Aspectos clinicopatológicos de 620 casos neurológicos de cinomose em cães. Pesquisa Veterinária Brasileira, Seropédica, v. 27, n. 5, p. 215-220, 2007.

VANDEVELDE, M.; CACHIN, M. The neurologic form of canine distemper. In: KIRK, R. W.; BONAGURA J. D. Current veterinary therapy, small animal practice. Philadelphia: Saunders, 1993. v. 11, p. 1003-1007. 
